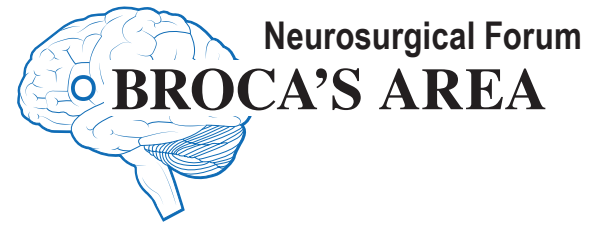

\section{Is life worth living? Decompressive craniectomy and the disability paradox}

\author{
Stephen Honeybul, FRCS, FRACS, ${ }^{1}$ \\ Grant R. Gillett, FRACS, MPhil, ${ }^{2}$ Kwok M. Ho, FCICM, PhD, ${ }^{3}$ \\ Courtney Janzen, MOT, ${ }^{4}$ and Kate Kruger, BSc (OT) ${ }^{4}$
}

1Department of Neurosurgery, Sir Charles Gairdner Hospital, Nedlands, and Royal Perth Hospital, Perth; ${ }^{3}$ Department of Intensive Care Medicine and School of Population Health, University of Western Australia, Perth; ${ }^{4}$ Department of Occupational Therapy, Sir Charles Gairdner Hospital, Perth, Western Australia; and ${ }^{2}$ Dunedin Hospital and Otago Bioethics Centre, University of Otago, Dunedin, New Zealand

A GOOD quality of life may mean many things to different people; however, a common assumption is that it is associated with good health, subjective well-being, and life satisfaction. ${ }^{9}$ Health and happiness represent value judgments that are made on a day-to-day basis in medicine, where the former is taken to have significant implications for the latter and, at the extremes, to largely determine whether a life is worth living. Indeed, people go to great lengths to achieve good health through measures such as lifestyle changes, good diet, and exercise, implying that good health equates with happiness and that ill health and disability are associated with a poor quality of life and suffering. ${ }^{21}$ Many forward-looking concepts such as that of an advance directive about health care decisions, and choices about whether to undergo certain procedures, are predicated on that apparently simple contrast.?

However, the reality is that patients' perceptions of personal health, well-being, and life satisfaction are often discordant with their objective health status. ${ }^{1,2}$ The disability paradox reflects the observation that many people with serious and persistent disabilities report a good or excellent quality of life, when to most observers they would appear to live in a very undesirable state..$^{19,25,26}$

A contemporary example has been demonstrated in the context of decompressive craniectomy. Over the past 2 de- cades, numerous studies have reported use of the procedure most commonly in the context of severe traumatic brain injury (TBI) and stroke, but also following subarachnoid hemorrhage and intracranial infection. ${ }^{12}$ Overall, there would appear to be little doubt that it can represent a lifesaving intervention; however, it will not reverse the initial neurological insult, and the concern among neurosurgeons has always been that in certain cases it may merely convert death into survival with severe disability and a quality of life that patients and their families may believe to be unacceptable. ${ }^{5,8,11}$ The implication of this assumption is that if the patient had known their eventual outcome they would not have provided consent. The example is telling because it calls into question one of the most prevalent justifications for discontinuation of rescue and life-sustaining care, even when that is couched in terms of the forwardlooking choices of the patient concerned. ${ }^{7}$

The clinical and ethical issues that arise from this dilemma are further compounded by the limitations inherent in quality of life and outcome assessment. For many years the Glasgow Outcome Scale and modified Rankin Scale (mRS) have been the most widely used assessment tools, and most studies dichotomize outcome into favorable or unfavorable categories. ${ }^{24}$ The obvious corollary is that unfavorable outcome equates with unacceptable in terms of a quality of life that is "worth living." Indeed, the senior authors (S.H. and G.R.G.) have argued on numerous occasions that this is a reasonable position to adopt on behalf of a notional "objective" patient. ${ }^{11}$

However, the results of two recent studies have demonstrated that adoption of this position may be inherently problematic and may serve to reinforce the concept of the disability paradox.

\section{Survival With Unfavorable Outcome}

A number of studies have been conducted in which patients who have survived following a decompressive craniectomy have been asked whether they regret having had the surgery. A positive response has been taken to indicate that they are satisfied with their outcome and that they would provide so-called retrospective consent. ${ }^{17}$ This issue 
has been investigated most extensively among patients who have survived after undergoing a decompressive hemicraniectomy for malignant ischemic stroke. ${ }^{10,20}$ In a systematic review, Rahme et al. asked the question "Is life worth living?" and found that despite high rates of physical disability, most patients did not regret having had surgery and were satisfied with their quality of life. ${ }^{23}$

More recently the same question was asked among a small group of patients who had survived with severe disability following decompressive craniectomy for severe TBI. ${ }^{15}$ These individuals were drawn from a cohort of 186 patients who had required a decompressive craniectomy for severe TBI between the years 2004 and 2010 at either Royal Perth Hospital or Sir Charles Gairdner Hospital in Western Australia. At 18-month follow-up, 75 patients had made a good recovery (40\%), 32 were moderately disabled (17\%), 34 were severely disabled (18\%), 5 were in a vegetative state (3\%), 32 had died (17\%), and 8 were lost to follow-up (4\%). ${ }^{15}$

At the time of the study it was at least 3 years following surgery, and the 39 patients who had been either severely disabled or in a vegetative state at 18 months were contacted and invited to participate. Among this small cohort, 7 patients had died, 12 were lost to follow-up, and 20 patients agreed to participate. Among those patients who could respond, most replied positively. A reasonable inference would be that they were also satisfied with their outcome, and that conclusion seems to be confirmed by the quality of life assessments that indicated significant ongoing physical disability but near-normal scores for general health, vitality, and mental health.

The responses were, at least to the senior investigators, surprising-however, they seem to endorse the observation that objective health status as assessed by health care professionals does not necessarily affect well-being as dramatically as would normally be thought. These studies would seem to confirm the "disability paradox" and the possible limitations of forward-looking or prospective declarations of health care preferences as reflected in advance directives. However, the question remains: can these results provide a justification for a lifesaving intervention that converts death into survival with severe disability?

\section{The Validity of Retrospective Consent}

Obtaining a positive response when asking a person whether they would retrospectively agree to an intervention that has enabled them to survive, albeit with considerable loss of neurological function, certainly demonstrates the ability of the human will to adapt to adversity. However, it would be injudicious and perhaps misguided to interpret this as a variation of the consent process, and this problem was clearly demonstrated by the findings of the recent DESTINY II study. ${ }^{16}$ That trial compared decompressive hemicraniectomy with standard medical management in patients over the age of 60 years who developed "malignant" middle cerebral artery infarction. The investigators found that among survivors, $63 \%$ of those in the hemicraniectomy group would provide retrospective consent to treatment, and they concluded that "Hemicraniectomy increased survival without severe disability." These findings would appear to support the ongoing use of the procedure in this age group because it is difficult to argue that it is not in a patient's best interest to have surgery if they are able to state that they are satisfied with their outcome and they would do the same again. However, closer examination of the results showed that of the 27 survivors in the hemicraniectomy group, only 11 could adequately answer the question. The remaining 16 had to have a surrogate response from their next of kin because they could not adequately answer due to either severe aphasia or neuropsychological deficits. Given that only $7 \%$ (2 patients) achieved an $\mathrm{mRS}$ score of 3 , the remaining 25 patients had an mRS score of either 4 or 5. Assuming that those patients with an mRS score of 3 responded positively, among the remaining 25 patients, 16 could not walk without assistance, could not take care of their basic bodily needs, and did not have sufficient neurocognitive function that they could answer a relatively simple question. We would contend that rather than accepting this as a variation of the consent process and thereby justifying an intervention that converts death into survival with severe disability, these findings merely highlight the limitations inherent in determining the satisfaction of patients with a severe disability, especially in the context of global aphasia.

The fundamental difficulty is that in the case of either ischemic stroke or severe TBI the requirements of informed consent are challenged because the patient is in no position to participate in discussions regarding their health care preferences. The background to these requirements and the challenge posed by a patient in this situation is the indispensable assumption that the person before us at any moment has forward-looking preferences that are determinative of their best interests. That intuition is captured by the concept of critical interests, namely "convictions about what makes life good on the whole ... rather than just experiential preferences." This is based on the premise that each of us at any one time has a set of convictions and judgments about value that are intrinsic to whom we are. ${ }^{6}$

In an attempt to investigate this further, a number of studies have canvassed opinion among health care workers regarding the acceptability or otherwise of survival with severe disability following decompressive craniectomy in the context of either severe TBI or ischemic stroke. ${ }^{13,14}$ The findings were that the majority of respondents were of the opinion that this would be unacceptable, and that they would not provide consent for surgery.

It may be that in the context of an acute neurological injury those preferences may change such that a particular individual may settle for a lesser quality of life in which that which was previously critical for their unique identity has been lost. However, this cannot add determinative weight to the argument that surgery should go ahead without full consideration being given to the known wishes of a particular individual. Indeed, to do so would undermine the premise on which documents such as living wills and advance directives have been based?

The difficulty arises when surgery is being considered in the case of an acute neurological emergency in a young person who is unlikely to have voiced, let alone documented, their health care preferences. 


\section{The Disability Paradox}

As previously stated, it is difficult to argue that it was not in a person's best interest to intervene surgically if that person is able to state that they are satisfied with the eventual outcome. It could be argued that patients may have lost a great deal of their higher functioning, mental ability, and insight- to the extent that they are unable to fully appreciate their level of disability. However, adopting that position implies that we ought not to discriminate against people with neurocognitive disability but instead should try to appreciate their differently oriented set of values. ${ }^{18}$ Indeed, based on the disability paradox, an alternative approach to outcome assessment that entails a more holistic notion of quality of life may need to be considered. ${ }^{22}$

The salutogenic model for health is an alternative approach to outcome assessment that focuses on a person's ability to adapt to circumstances that they may previously have thought to be unacceptable. ${ }^{3,4}$ It is a stress resourceoriented concept that seeks to explain why people can stay well despite stressful situations and physical hardships. In many ways it is the opposite response to traditional assessments of disability that tend to focus on its pathological aspects and the ability or otherwise of an individual to perform physical tasks.

The salutogenic model focuses more on resilience of the human spirit in the face of adversity, and there are 2 core concepts; namely, the "sense of coherence" and the "generalized resistance resources."

The sense of coherence reflects a person's view of life and their capacity to deal with difficult or stressful situations. There are 3 core elements: 1) comprehensibility, which embodies a belief that a person can understand events in their life; 2) manageability, which is a belief that a person has the necessary skills or, perhaps more importantly, the necessary support so that they have some level of control of their lives; and 3) meaningfulness, which implies a belief that things in life are interesting and worthwhile, and that there is good reason or purpose to care about what happens. In context of survival following decompressive craniectomy, it is perhaps the last element that is most important. If a person has no sense of meaning, they will have no motivation to comprehend and manage challenging events such as adapting to disability.

The generalized resistance resources are factors such as money, self-confidence, and (perhaps most importantly) social support that help a person combat a range of psychosocial stressors.

It has to be acknowledged that no assessment tool in itself will improve outcome. However, focusing on a person's abilities to adapt and take value from their surroundings may improve their capacity to cope with a level of disability that they might previously have deemed unacceptable, and this in some way helps explain the disability paradox. If a person has the necessary resources in terms of social and financial support, they can develop a strong enough sense of coherence that they value their life and find it meaningful. If this can be achieved in those patients who survive with a so-called unfavorable outcome, they themselves may not necessarily consider it to be unacceptable.

However, it must be acknowledged that this is not always the case. Although Rahme et al. ${ }^{23}$ found that most patients and their families would provide retrospective consent, this was not always the case. Also, the positive responses will be biased toward those patients who have enough residual neurocognitive function that they can provide a response. Likewise, in the cohort of patients who survived following severe TBI, 12 of the 39 eligible patients had been lost to follow-up. It may be that they were unwilling to participate because they and their caregivers were not satisfied with their eventual outcome, or they may have gone on to achieve a greater level of independence. In addition, the responses of the 13 patients who were severely disabled cannot necessarily be extrapolated to all survivors, especially those who remain in a vegetative state.

Overall there is unlikely to be a one-size-fits-all approach to the complicated issue of quality of life and outcome assessment. For some, life is sacrosanct and worth protecting at any cost, whereas for others the loss of cognitive function and independence would be intolerable. Unfortunately the time and clinical setting in which these issues need to be considered is both limited and emotionally distressing. In these circumstances, acknowledging the disability paradox and accepting the uncertainty may go some way to lessen some of the burden often felt by those involved in these difficult decisions.

\section{Conclusions}

The debate will continue regarding the ongoing use of a procedure that is lifesaving but may leave a person with a level of disability that they antecedently would have deemed unacceptable. The disability paradox cannot usurp the need to determine prior to surgical intervention whether the most likely outcome would be acceptable to the person on whom the procedure is being performed, and obtaining retrospective consent cannot validate that intervention. However, in cases in which there is uncertainty regarding either outcome or a patient's known wishes, recognizing the disability paradox may be useful. For those who survive, the use of more holistic assessments focusing on a person's strengths and abilities rather than their disabilities may help relieve some of the isolation often felt by patients and their families on the long road to recovery.

\section{References}

1. Albrecht GL, Devlieger PJ: The disability paradox: high quality of life against all odds. Soc Sci Med 48:977-988, 1999

2. Albrecht GL, Higgins PC: Rehabilitation success: the interrelationships of multiple criteria. J Health Soc Behav 18:36-45, 1978

3. Antonovsky A: Complexity, conflict, chaos, coherence, coercion and civility. Soc Sci Med 37:969-974, 1993

4. Antonovsky A: The structure and properties of the sense of coherence scale. Soc Sci Med 36:725-733, 1993

5. Cooper PR, Rovit RL, Ransohoff J: Hemicraniectomy in the treatment of acute subdural hematoma: a re-appraisal. Surg Neurol 5:25-28, 1976

6. Dworkin R: Life's Dominion. An Argument about Abortion and Euthanasia. London: Harper Collins, pp 127-135, 1993

7. Gillett G, Walker S: The evolution of informed consent. J Law Med 19:673-677, 2012

8. Gillett GR, Honeybul S, Ho KM, Lind CR: Neurotrauma and 
the RUB: where tragedy meets ethics and science. J Med Ethics 36:727-730, 2010

9. Goode D: The National Quality of Life for Persons with Disabilities Project: a quality of life agenda for the United States, in Goode D (ed): Quality of Life for Persons With Disabilities. Cambridge: Brookline Press, pp 139-161, 1994

10. Holtkamp M, Buchheim K, Unterberg A, Hoffmann O, Schielke E, Weber JR, et al: Hemicraniectomy in elderly patients with space occupying media infarction: improved survival but poor functional outcome. J Neurol Neurosurg Psychiatry 70:226-228, 2001

11. Honeybul S, Gillett GR, Ho K: Futility in neurosurgery: a patient-centered approach. Neurosurgery 73:917-922, 2013

12. Honeybul S, Ho KM: The current role of decompressive craniectomy in the management of neurological emergencies. Brain Inj 27:979-991, 2013

13. Honeybul S, Ho KM, Blacker DW: ORACLE Stroke Study: Opinion regarding acceptable outcome following decompressive hemicraniectomy for ischemic stroke. Neurosurgery [epub ahead of print], 2015

14. Honeybul S, Ho K, O'Hanlon S: Access to reliable information about long-term prognosis influences clinical opinion on use of lifesaving intervention. PLoS One 7:e32375, 2012

15. Honeybul S, Janzen C, Kruger K, Ho KM: Decompressive craniectomy for severe traumatic brain injury: is life worth living? J Neurosurg 119:1566-1575, 2013

16. Jüttler E, Unterberg A, Woitzik J, Bösel J, Amiri H, Sakowitz OW, et al: Hemicraniectomy in older patients with extensive middle-cerebral-artery stroke. N Engl J Med 370:1091-1100, 2014

17. Kiphuth IC, Köhrmann M, Lichy C, Schwab S, Huttner HB: Hemicraniectomy for malignant middle cerebral artery infarction: retrospective consent to decompressive surgery depends on functional long-term outcome. Neurocrit Care 13:380-384, 2010
18. Kottke FJ: Philosophic considerations of quality of life for the disabled. Arch Phys Med Rehabil 63:60-62, 1982

19. Lacey HP, Fagerlin A, Loewenstein G, Smith DM, Riis J, Ubel PA: Are they really that happy? Exploring scale recalibration in estimates of well-being. Health Psychol 27:669675,2008

20. Leonhardt G, Wilhelm H, Doerfler A, Ehrenfeld CE, Schoch $\mathrm{B}$, Rauhut F, et al: Clinical outcome and neuropsychological deficits after right decompressive hemicraniectomy in MCA infarction. J Neurol 249:1433-1440, 2002

21. Levine S: The changing terrains in medical sociology: emergent concern with quality of life. J Health Soc Behav 28:1-6, 1987

22. Nelson HL: What child is this? Hastings Cent Rep 32:2938,2002

23. Rahme R, Zuccarello M, Kleindorfer D, Adeoye OM, Ringer AJ: Decompressive hemicraniectomy for malignant middle cerebral artery territory infarction: is life worth living? J Neurosurg 117:749-754, 2012

24. Rogers SJ, Browne AL, Vidovich M, Honeybul S: Defining meaningful outcomes after decompressive craniectomy for traumatic brain injury: existing challenges and future targets. Brain Inj 25:651-663, 2011

25. Ross CE, Van Willigen M: Education and the subjective quality of life. J Health Soc Behav 38:275-297, 1997

26. Ubel PA, Loewenstein G, Schwarz N, Smith D: Misimagining the unimaginable: the disability paradox and health care decision making. Health Psychol 24 (4 Suppl):S57-S62, 2005

\section{Disclosures}

The authors report no conflict of interest. 